\title{
Identidade é o território organizado e assegurado pela memória e pelas narrativas
}

\author{
Identity is the organized territory that is ensured \\ by the memory and by the narratives
}

\section{La identidad es el territorio organizado y asegurado por la memoria y por las narrativas}

\section{Paulo Nassar}

- Pós-doutor pela Libera Università di Lingue e Comunicazione, Milão, Itália

- Doutor e mestre em Ciências da Comunicação, na área de Relações Públicas, pela Escola de Comunicações e Artes da Universidade de São Paulo (ECA-USP)

- Graduado em Jornalismo pela Pontifícia Universidade Católica de São Paulo (PUC-SP)

- Professor livre-docente da ECA-USP

- Autor, entre outros, de O que é comunicação empresarial, Relações públicas na construção da responsabilidade histórica e no resgate da memória institucional das organizações e Comunicação todo dia

- Coordenador do Grupo de Estudos de Novas Narrativas (Genin), da ECA-USP

- $\quad$ Diretor-presidente da Associação Brasileira de Comunicação Empresarial (Aberje)

- E-mail: paulonassar@usp.br

Rodrigo Silveira Cogo

- Mestre em Ciências da Comunicação pela Escola de Comunicações e Artes da Universidade de São Paulo (ECA-USP)

- $\quad$ Especialista em Gestão Estratégica em Comunicação Organizacional e Relações Públicas pela ECA-USP

- Graduado em Relações Públicas pela Universidade Federal de Santa Maria (UFSM)

- Professor nos cursos de especialização em Gestão em Comunicação Empresarial da Aberje e da Escola Superior de Engenharia e Gestão (Eseg)

- Gerente de Conteúdo para interfaces digitais, da Associação Brasileira de Comunicação Empresarial (Aberje)

- E-mail: rodrigocogo@usp.br 


\section{Resumo}

Relações mais abertas e cooperativas dentro das organizações, com fluidez a múltiplas vozes e baseadas na confiança, deve ser alvo do planejamento de comunicação. Para conhecer uma empresa, avaliá-la com coerência e responsabilidade, é preciso olhar sua trajetória no tempo, na perspectiva histórica, que contém todas as responsabilidades - cumpridas ou não. Este artigo faz uma discussão teórica sobre a força da memória organizacional como legitimadora das diretrizes comunicacionais e do storytelling como recurso narrativo de confiança e de identidade, dando base às organizações polifônicas.

\section{PALAVRAS-CHAVE: COLABORAÇÃO・DIÁLOGO • MEMÓRIA •NARRATIVAS・IDENTIDADE.}

\section{Abstract}

More open and cooperative relations within organizations, with multiple voices and fluidity based on trust, should be the target of the communication planning. To know a company, evaluate it with consistency and accountability, we need to look their trajectory in time, in historical perspective, which contains all the responsibilities - accomplished or not. This article presents a theoretical discussion of the strength of organizational memory as legitimizing of communication guidelines and storytelling as a narrative feature of trust and identity, giving basis for polyphonic organizations.

\section{KEYWORDS:COLLABORATION・DIALOGUE・MEMORY •NARRATIVE・IDENTITY.}

\section{Resumen}

Relaciones más abiertas y de cooperación dentro de las organizaciones, con múltiples voces y basadas en la confianza, deben ser el objetivo de la planificación de la comunicación. Para conocer una empresa, evaluarla con coherencia y responsabilidad, tenemos que mirar su trayectoria en el tiempo, en una perspectiva histórica, que contiene todas las responsabilidades - realizadas o no. En este artículo se presenta una discusión teórica de la fuerza de la memoria de la organización como una legitimación de las pautas de comunicación y la narración como una característica de la narrativa de la confianza y la identidad, dando base para organizaciones polifónicas. 


\section{ANO $11 \cdot$ NÚMERO 20 • 1 SEM. 2014 • ORGANICOM \\ IDENTIDADE É O TERRITÓRIO ORGANIZADO E ASSEGURADO \\ PELA MEMÓRIA E PELAS NARRATIVAS}

$A^{s}$

s transformações contemporâneas estão ocorrendo cada vez mais rápidas e com variados impactos em toda a sociedade. A competitividade das empresas sofre uma influência considerável dessas mudanças, entre outros fatores pela própria variedade de grupos de inter-relação e pela agilidade de circulação de informações em sociedades integradas globalmente. Como assinala José Cláudio Terra ([s.d.], "as empresas são muito mais porosas, histórias entram e saem de maneira muito mais rápida e com abrangência muito maior". Os públicos se encontram numa "situação de fragilidade de identidade, de enfraquecimento de vínculos sociais diversos, de busca de sentido, de desorientação quanto ao presente e ao futuro e de carência de referenciais" (Freitas, 2000, p. 57). Como diz Tereza Halliday (2009, p. 46), os públicos-alvo são "co-atores em construção da legitimidade organizacional, ou seja, da tessitura do consenso para que a organização seja e continue a ser bem aceita como agente econômico, social, cultural e político". E é nesta perspectiva que este artigo é apresentado: para oferecer reflexões, a partir de determinado conjunto teórico contemporâneo e transdisciplinar, e buscar contribuir com insights para tecer os laços entre memória, identidade e comunicação organizacional em tempo de polifonia ?

\section{MÚLTIPLAS VOZES E REDES DE RELACIONAMENTO}

A complexidade e as incertezas de cenário fazem as organizações buscarem formatos de gerenciamento baseados num intenso diálogo e no engajamento de seus públicos de interesse. A construção de redes de relacionamento parte de relações humanas mais abertas e cooperativas, com base em um planejamento que posiciona a comunicação em patamar estratégico e que dá fluidez a múltiplas vozes. É isto que sinaliza o conceito de polyphonic organization proposto por Martin Kornberger, Stewart Clegg e Chris Carter (2006), considerando essa multiplicidade a partir dos públicos de relacionamento de uma organização e, por consequência, a variedade dos discursos que constituem sua realidade. Esses pesquisadores igualmente aludem às vozes silenciadas pelos discursos hegemônicos e entendem que, através da polifonia, é possível estar apto a compreender mudanças nos padrões de organização entre as pessoas. Trata-se da noção de organização como sistemas verbais construídos socialmente, arenas nas quais uma variedade de tramas simultâneas e descontínuas ocorre por diversos atores. Daí deriva toda uma preocupação com o que é dito e como é dito: "0 argumento é que organizações são culturas e constantemente precisam de traduções, não só intraorganização e seus espaços discursivos, mas também interorganizações"2 (Kornberger; Clegg; Carter, 2006, p. 7, tradução nossa). Além disto, deriva uma reflexão acerca da disposição em ter unidade de discurso como estratégia essencial para o cuidado com a reputação - o que continua importante, mas não sem se dar conta de que grandes narrativas, como registro linguístico único, podem facilmente inibir, proibir, limitar, dirigir e prescrever de maneira frontalmente oposta à necessidade polifônica. Por isso, é tão pertinente a visão de Paulo Nassar (2012, p. 132), quando fala sobre o mundo das relações públicas democráticas como "espaço onde a comunicação organizacional valoriza e incorpora a opinião de seus públicos e da sociedade e onde a história pode resgatar vivências e 0 indivíduo organizacional como protagonista de sua vida, da organização, da comunidade e do país".

Relações duradouras e valiosas para as organizações, em ambientes de instabilidade, estão relacionadas com questões fundamentais da administração, como a base sobre valores, missão e filosofia. Mas é pela comunicação que tudo se constrói e dissemina, demandando processos e formatos que gerem confiança. Como é possível adiantar, através da análise de estudos de Nassar (2009, p. 302),

10 filósofo russo Mikhail Bakhtin desenvolve o conceito de polifonia em Problemas da poética de Dostoievski, lançado no Brasil pela Editora Forense em 1981. Significa a presença de outros textos dentro de um texto, causada pela inserção do autor num contexto que já inclui previamente textos anteriores que o inspiram ou influenciam. Ao enfatizar o caráter dialógico do universo artístico de Fiodor Dostoievski, Bakhtin destaca procedimentos especiais de construção narrativa, como a inconclusibilidade temática, a independência e a equipotência de vozes.

2 Tradução nossa. 
o depoimento de vida que nasce no âmbito dos públicos, das redes sociais ou da sociedade tem um alto valor para a formação da confiança na empresa ou instituição, porque é percebido pelos receptores como distante dos interesses das organizações e, também, compatível com os interesses dos receptores.

É com este escopo que se pode falar nos processos narrativos, na memória e na formação ou consolidação de identidade.

\section{REFLEXÕES SOBRE MEMÓRIA}

A consolidação de um cenário de fragmentação, com indivíduos perdidos no seu sentido de existir, traz efeitos diretos na forma com que as organizações se comunicam. Diante da crença na relevância da responsabilidade histórica como ativo reputacional e identitário, é importante para os comunicadores adensarem conhecimentos nesse campo.

Pode-se definir memória como um conjunto de funções cerebrais que permitem ao homem guardar as mensagens, mas há que se levar em conta a permanente possibilidade de seleção desses conteúdos antes de sua evocação. É de fortes sentimentos e emoções que memórias diversificadas irrompem e invadem a cena pública, buscando reconhecimento, visibilidade e articulação. Em geral, suprem um espaço que a racionalidade história é impotente para exprimir, "atualizando no presente vivências remotas (revisitadas, silenciadas, recalcadas ou esquecidas) que se projetam em relação ao futuro" (Seixas, 2001, p. 98), dentro de uma noção de que "memória é o lugar das articulações factuais e das impressões subjetivas sobre o vivido" (Meihy, 2010, p. 181-182).

Pierre Nora (1993, p. 9) refere-se quase efusivamente a um conceito de memória:

É a vida, sempre carregada por grupos vivos e, nesse sentido, ela está em permanente evolução, aberta à dialética da lembrança e do esquecimento, inconsciente de suas deformações sucessivas, vulnerável a todos os usos e manipulações, suscetível de longas latências e de repentinas revitalizações.

Para Marieta de Moraes Ferreira (2004, p. 98), memória é um elemento constitutivo do sentimento de identidade, tanto coletivo quanto individual, como fruto de um trabalho de construção constantemente negociada e representação de um fenômeno social. Gilberto Velho (2001, p. 11) reforça taxativo, afirmando que "não existe vida social sem memória, a própria possibilidade de interação depende de experiências e expectativas culturalmente compartilhadas". Para ele, não se trata de um único relato ou história, mas uma composição de discursos e representações das sociedades complexas, com versões que expressam a heterogeneidade dos atores. Por isso, é nessa relação entre a rede de significados e a dimensão da ação dos atores sociais que deve ser caracterizada a importância das memórias.

É do filósofo francês Henri Bergson (1999) que vem uma outra proposta para diferentes tipos de memória. Por "memóriahábito" ele entende os esquemas de comportamento guardados pelo corpo, como mecanismos motores. É adquirida pelo esforço da atenção e pela repetição de gestos ou palavras, dentro de um panorama de adestramento cultural. Já a "memória-pura" traria à consciência - por um relampejo não exatamente voluntário, porque latente nas zonas do psiquismo - um momento único, singular e irreversível da vida. Seria como uma memória sem considerar o impacto de um contexto presente da lembrança. 
Maurice Halbwachs (2004) oferece um complemento importante: o tratamento da memória como fenômeno social, ou seja impactada pela realidade circundante do recordador, sobremaneira no contato com grupos de convívio e de referência. 0 caráter livre da memória ficaria relativizado, já que ela não seria um reviver, mas sim refazer, reconstruir, repensar, dentro de referências influenciadas pelo presente em novos juízos de realidade e valor. Assim, é fácil compreender a impossibilidade de reviver o passado tal como se apresentou. Trata-se de um limite imposto pelo tempo e pelo conhecimento acumulado, que na verdade então passam a reconstruir a fisionomia dos acontecimentos. Além disto, intervêm todas as marcas do grupo social.

\section{O PROCESSO NARRATIVO DA ESTRATÉGIA E DA TRANSCENDÊNCIA NA RESPONSABILIDADE HISTÓRICA ${ }^{3}$}

Thomaz Wood Jr. (1996, p. 23), em total consonância com o escopo deste trabalho, assinala que estratégia é "um padrão de comportamento, algo que se constrói ao longo da história da empresa, algo com raízes no passado". Ou, como assinalam David Barry e Michael Elmes (1997, p. 433),

Estratégias podem ser examinadas como artefatos: sua retórica, metáforas e sequências podem ser identificadas, comparadas e avaliadas de diferentes formas. Estratégias podem ser examinadas como um processo narrativo, no qual histórias sobre diretrizes são apropriadas e defendida .

Mats Alvesson e Stanley Deetz (2007, p. 252) veem visões e cultura corporativas como "construções de narrativas locais e estratégicas para promover a integração e a motivação em uma sociedade pluralista". É o entendimento de como a linguagem é usada para construir sentido e como os stakeholders criam um discurso de direção-como o relato da estratégia influencia as escolhas e ações consequentes. Howard Gardner (apud Barry e Elmes, 1997, p. 434) resume bem quando diz que o desafio dos líderes visionários é oferecer uma história que construa "a mais confiável síntese do passado, o revisite com a luz das questões do presente, deixe aberto espaço para eventos futuros e permita contribuições individuais pelas pessoas do grupo" 5. Nesse sentido, desejar modelos de leitura das atitudes organizacionais presume a existência de um modelo de linguagem e de autoridade que tem cada vez menos espaço na pluralidade do mundo atual - em que credibilidade e confiança são quesitos que devem ser reconhecidos pelos outros a partir de suas percepções. É como dizem Barry e Elmes (1997, p. 438): "narrativas estratégicas têm vida própria".

Joan Costa (1995, p. 16) converge com a ideia de empresa como organismo vivo e sistema de comunicação, em que a "comunicação corporativa é, em sua essência, efeito da integração sinérgica das comunicações empresariais, a revolução dos serviços e seus instrumentos tecnológicos"6 . Trata-se, pois, de um enfoque de comunicação que transcende a própria organização para permitir repensar suas fronteiras, numa reconceituação de seu modo de ser e atuar. É como manifesta Michel Maffesoli (2003, p. 13), entendendo que "a comunicação estratégica organizacional se consubstancia nesta visão

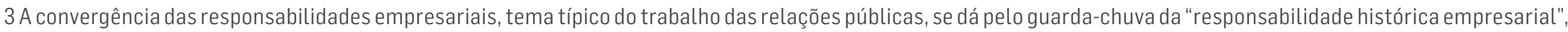

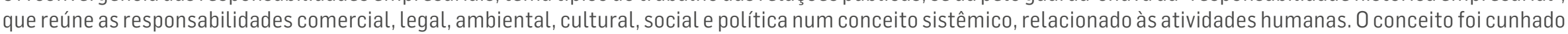

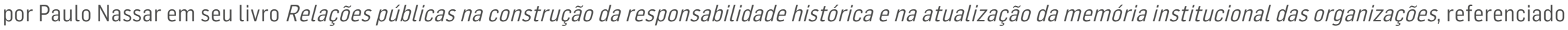

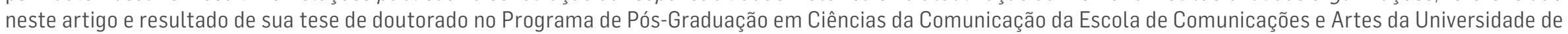
São Paulo.

4 Tradução nossa.

5 Tradução nossa.

6 Tradução nossa. 
ampla do entorno pertencente à organização, onde a comunicação é o que faz a relians", religação como elo entre os ambientes interno e externo. Portanto, para responder à sociedade com legitimidade, de maneira que ela possa preencher ambas as necessidades e preservar, planejar e agir de forma a manter indefinidamente as condições indispensáveis para a vida atual e futura,

é preciso que a empresa seja vista a partir de uma linha do tempo, na qual se possa fazer uma análise atitudinal, se perceba a energia dinâmica que transita entre passado e futuro, que permite entender o presente e inferir quais impactos serão gerados (Nassar, 2007).

Para conhecer uma empresa, avaliá-la com coerência e responsabilidade, crer no seu discurso e estabelecer uma relação de confiança, é preciso olhar sua trajetória no tempo, na perspectiva histórica, que contém todas as responsabilidades cumpridas ou não. Não é uma comunicação pontual e instrumental, com objetivos de curto prazo desconectados de uma visão global, mas sim uma postura holística que parte do princípio de que é preciso conhecer a empresa por inteiro, seus interesses e suas necessidades e perceber as identidades em trânsito. Ao mesmo tempo, é necessário antever e identificar as mudanças e a evolução de mercado, utilizando essas informações para conscientizar a própria organização e todos os públicos ligados direta ou indiretamente a ela sobre seus papéis e suas responsabilidades. Tudo respaldado na essência da interação comunicacional dialógica, "ao reconhecer a organização como um dos interlocutores do processo comunicacional, ao lado de outros atores sociais" (Oliveira, 2007, p. 52).

Este artigo busca evidências da força da memória organizacional como legitimadora das diretrizes comunicacionais e do storytelling como recurso narrativo de confiança e de identidade. Afinal, a temporalidade hoje, como diz Olgária Matos (1998, p. 29), "é de um presente opaco, sem passado, plasmado, petrificado" e, por ser espacializado, fragmentado e repetitivo, o cotidiano não traz o encantamento necessário para obter atenção num cenário de instabilidade e múltiplos apelos concorrentes. Nesse sentido, o comunicador precisa ter cuidado, porque "a eterna mudança é inimiga da memória, tornando-a supérflua em um mundo no qual o homem é tratado como mera função, como business" (Matos, 1998, p. 30).

A análise de Ana PaulaG. Ribeiro e Marialva Barbosa (2007, p. 102) aponta para o papel ocupado nas sociedades contemporâneas pela mídia, que, com suas complexas redes de informação e acelerados ritmos de transformação tecnológica, pareceria induzir - pelo desejo de fruição plena no presente - ao enfraquecimento da consciência história. A pós-modernidade enfatizaria a perda da memória e da referencialidade histórica como uma das marcas do tempo atual. Nessa linha, projetando como seriam as organizações pós-modernas, o sociólogo italiano Giovani Lanzara (apud Andrade, 2005, p. 633) diz que são aquelas "que não têm passado ou futuro, que vivem no presente, não contam histórias sobre si mesmas e não projetam sua imagem no futuro, tudo jogando no presente". Sobre isto completam Ribeiro e Barbosa (2007, p. 103):

A modernidade inaugura um novo regime de memória, multiplicando os espaços de rememoração que (...) refletem o desejo de ancorar um mundo em crescente mobilidade e transformação e de compensar a perda dos elementos mais sólidos e concretos que, antes, serviam de referência para os sujeitos.

A aceleração do tempo e a preocupação com a perda de sentido do passado e o próprio aumento da capacidade de esquecer têm levado as sociedades contemporâneas a demonstrar grande interesse em recuperar a memória e também a história. 0 enfraquecimento das chamadas "grandes narrativas", organizadoras da coesão social, levou a uma regressão das memórias fortes, gerais, totalizadoras, em proveito de memórias múltiplas e fragmentadas (Ribeiro; Barbosa; 2007, p. 105). 
Por tudo isso, a importância de equilíbrio entre pretensões futuras e os traçados do passado fica cada vez mais clara, daí derivando uma verdadeira "moda da memória", com toda a sorte de influências. Vale referir que o emprego dessa expressão nesta pesquisa não significa modismo passageiro, ou então no sentido de "obsessão da memória de Fausto Colombo (1991). A "moda da memória" é posta como uma valoração do passado, como diz Paul Thompson (1992, p. 194-195).

Nosso modo de vida, nossa personalidade, nossa consciência, nosso conhecimento constroem-se diretamente com nossa experiência de vida passada. Nossas vidas são a acumulação de nossos passados pessoais, contínuos e indivisíveis.

Ana Maria H. Baptista e Glaucia R. Pereira (2007, p. 305) definem bem a questão: o homem é um ser imerso em temporalidades e, portanto, associado a subjetividade, identidade, memória e diferença. E também o tempo pode ser subjetivo, ligado especialmente ao mundo interior e regido pelos ritmos das sensações e impressões pessoais desencadeando numa memória individual, sendo qualitativo e não mensurável.

É preciso destacar que o campo da memória, como será esmiuçado no próximo item, e inclusive da própria comunicação organizacional se nutre de uma inspiração rizomática (Deleuze; Guattari, 1995), porque se desenvolve numa diversidade de interfaces. 0 rizoma é apresentado como multiforma, uma haste subterrânea com ramificações variadas de superfície e com bulbos ou tubérculos, e nesse sentido superando a visão de raiz, de ponto único de eclosão. A memória postula justamente a multiplicidade e a convivência de diversos sujeitos, que reconstroem experiências passadas, à luz ou não das intenções do presente. Isso combina imensamente com os princípios dessa nova concepção de comportamento e inteligência: "as multiplicidades são rizomáticas e denunciam as pseudomultiplicidades arborescentes. (...) não têm sujeito nem objeto" (Deleuze; Guattari, 1995, p. 15). A metáfora do mapa é empregada pelos autores, apresentando sintonia com a memória como algo conectável em todas as direções, desmontável, reversível e suscetível a modificações, visto que, conforme comentam, "uma das características mais importantes do rizoma talvez seja a de ter sempre múltiplas entradas" (Deleuze; Guattari, 1995, p. 21). Não combina, portanto, com os sistemas pensados a partir da árvore ou da raiz, porque eles são hierárquicos e comportam centralidades de significância. Assim como a memória, o rizoma "não é feito de unidades, mas de dimensões. (...) não tem começo nem fim, mas sempre um meio pelo qual cresce e transborda" (Deleuze; Guattari, p. 31) e, nessa perspectiva, ambos têm como tecido a conjunção "e", não excludente. 0 rizoma se presta para entender a operação das organizações polifônicas já mencionadas.

\section{LAÇOS ENTRE MEMÓRIA E IDENTIDADE}

Podemos afirmar que, enquanto temos a capacidade intelectual de buscar, selecionar, interpretar e opinar acerca das informações com as quais convivemos, temos uma identidade assegurada. Trata-se de uma afirmação que vale também para as empresas e organizações. Essa operação que afirma a nossa identidade - e também das organizações - passa por um "eu", especial e único, envolve uma relação com um tipo de informação que posiciona esse "eu" diante de si mesmo, de outros, da sociedade, dos animais e da natureza. Uma operação que instiga o aparecimento, em nosso "eu", de um conjunto de informações pode ser denominada memória individual. No caso das empresas e instituições, a denominamos memória

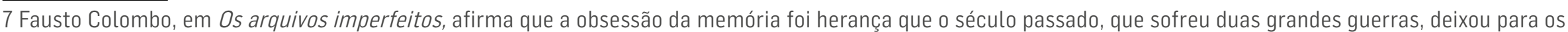

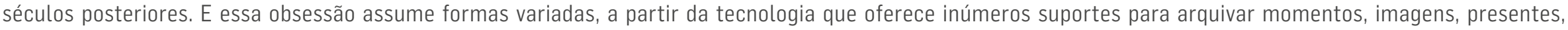

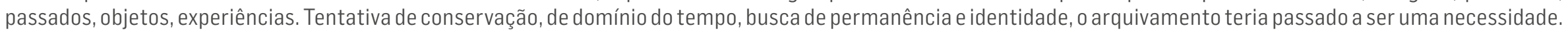


organizacional. Somos um turbilhão de lembranças aberto por algum dos nossos sentidos. Uma narrativa com as digitais de memórias, marcadas por identidade, por experiências, organizadas a partir de determinado ritmo, de um estilo, de um acervo de palavras, habilidades, técnicas e cultura.

Na capacidade individual de buscar as lembranças, transformá-las em narrativas onde o passado é reelaborado, trabalhado, com uma infinidade de sentidos, entre eles o de explicar, no presente, as nossas escolhas, é que, na visão de Jorge Luís Borges, está a ligação inseparável entre memória e identidade. Borges (1993, p. 29) argumenta:

\begin{abstract}
A identicidade pessoal reside na memória e perder a memória é perder aquela faculdade que inibe o cretinismo. Nós podemos pensar a mesma coisa com relação ao universo. Sem um espelho sensível e secreto a guardar o que se passa nas nossas almas, a história universal não é nada mais do que tempo perdido - e com ela nossa história, o que nos reduz de maneira desagradável à condição de fantasmas.
\end{abstract}

E diante da extensão do que pode ser memória "o que é definido oficialmente como 'passado' é e deve ser claramente uma seleção particular da infinidade daquilo que é lembrado ou capaz de ser lembrado" (Hobsbawn, 1998, p. 23). Trata-se de uma advertência preciosa para empresas e instituições que muitas vezes querem excluir do universo das memórias organizacionais outras seleções de lembranças, como as dos integrantes da organização, os seus trabalhadores, e também a memória de outros públicos que cotidianamente se relacionam com essas organizações, entre outros, consumidores, comunidades e famílias. A empresa-vista como um território extensão da sociedade - tem inúmeras narrativas estruturadas além das memórias consideradas oficiais.

Podemos, ao menos, tentar estabelecer a partir de nossas memórias e de nossa identidade uma soberania informacional pessoal e, também, organizacional - uma soberania comunicacional e relacional estruturada em narrativas baseadas em nossas experiências -, diante de uma sociedade que tem entre as suas principais características a geração torrencial de informações, que prende todos aos acontecimentos do agora a uma bolha do presente. E, decorrente disso, é interessante nos lembrarmos de Marshall Mcluhan (1964), que trabalhou o tema da organização das informações a partir dos conceitos de meios quentes - que contêm grande quantidade de informações - e meios frios - que contêm pouca quantidade de informações -, de onde se pode retirar a esclarecedora citação sobre a psique e o comportamento humano diante da quantidade de informações. Para ele, "o aquecimento de um dos sentidos tende a produzir hipnose, o esfriamento de todos os sentidos redunda em alucinação" (McLuhan, 2006, p. 50). Vale a reflexão do sociólogo norte-americano Orrin E. Klapp, sobre a avalanche informacional que tira todo o significado e sentido. Preocupado com a relação entre entropia e informação, diz Klapp (apud Gianetti, 2008, p. 302-303):

A mídia despeja sobre nós uma avalanche de bits e sinais que, mesmo que soubéssemos o que fazer com eles, atingem-nos com rapidez excessiva para uma genuína assimilação. (...). 0 fato de que uma quantidade excessiva de bits seja despejada mais depressa do que você consegue assimilar significa manter-se indefinidamente em suspenso e restrito a fatos superficiais, incapaz de articular uma filosofia de vida coerente e profunda - fraudado de sentido.

Ou seja, é possível caracterizar a sociedade informacional como produtora de paralisia social, quando radicaliza o bombardeio de informações sobre o indivíduo. A novidade informacional incessante pode não levar a contexto nenhum. Vive-se no ponto, no acontecimento, numa vida sem história e sem geografia, que afasta de memórias individuais e sociais. Isso mostra a importância dos ambientes organizacionais, entre eles, os centros de memória e referência e as áreas de comunicação, onde ainda se pode fazer uma mediação qualificada entre as fontes de produção massiva de informações e as pessoas. 
O dilema do sujeito - do "eu", que quer se afirmar diante de um universo que esmaga a capacidade de uma identidade refletir sobre o sentido da informação - mostra a necessidade de se promover institucionalmente um ambiente político, social, econômico, tecnológico e comportamental democrático que se relacione de uma nova forma com as informações, com as memórias. Um ambiente crítico que questione a informação sem valor, constituído por profissionais de comunicação, da informação e da história que trabalhem contra a massificação de narrativas. E, nesse sentido, deem garantia da existência da polifonia nas organizações e não da continuidade de discursos unidirecionais e pretensamente hegemônicos - que, em tempos de sobrecarga informativa, correm o sério risco de sequer serem vistos. Tal qual o poeta Manoel de Barros (2010), postulam-se aqui comunicadores que "escovem as palavras", reconhecendo e protegendo as identidades individuais, sociais e organizacionais. Identidade que é o "eu" e a suas circunstâncias históricas, pois o "eu" sem história é apenas natureza.

\section{REFERÊNCIAS}

ALVESSON, Mats; DEETZ, Stanley. Teoria crítica e abordagens pós-modernas para estudos organizacionais. IN: CLEGG, Stewart; HARDY, Cynthia; NORD, Walter. Handbook de estudos organizacionais: modelos de análise e novas questões em estudos organizacionais. Vol.1. São Paulo: Atlas, 2007. p. 226-264.

ANDRADE, Rogério Ferreira de. Quando nos roubam o chão, obrigam-nos a voar: narrativas erosivas e extinção moral das organizações. In: SOPCOM, 4ํㅡ. Lisboa, 2005. Actas... Disponível em: <http://www.bocc.ubi.pt/pag/andrade-rogerio-quandoroubam-chao-obriga-nos-voar.pdf>. Acesso em: 06 mar. 2011.

BAPTISTA, Ana Maria Haddad; PEREIRA, Glaucia Rezende. Tempo-memória: algumas reflexões. Integração, a. XIII, n. 51, p. 305-308, out./nov./dez. 2007

BARROS, Manoel de. Memórias inventadas: as infâncias de Manoel de Barros. São Paulo: Planeta, 2010.

BARRY, David; ELMES, Michael. Strategy retold: towards a narrative view of strategic discourse. Academy of Management Review, v. 22, n. 2, p. 421-452, 1997.

BERGSON, Henri. Matéria e memória: ensaio sobre a relação do corpo com o espírito. 2. ed. São Paulo: Martins Fontes, 1999.

BORGES, Jorge Luis. História da eternidade. 2. ed. São Paulo: Globo, 1993.

COLOMBO, Fausto. Os arquivos imperfeitos. Trad. De Beatriz Borges. São Paulo: Perspectiva, 1991.

COSTA, Joan. Comunicación corporativa y revolución de los servicios. Madrid: Ediciones Ciencias Sociales, 1995.

DELEUZE, Gilles; GUATTARI, Félix. Mil platôs: capitalismo e esquizofrenia. Vol. 1. São Paulo: 34, 1995. 
FERREIRA, Marieta de Moraes. Memórias da história. Nossa História, São Paulo, Vera Cruz/Biblioteca Nacional, a. 1, n. 8. p.98ss, jun. 2004.

FREITAS, Maria Ester de. Cultura organizacional: identidade, sedução e carisma. 2. ed. Rio de Janeiro: FGV, 2000.

GIANNETTI, Eduardo. O livro das citações: breviário de ideias replicantes. São Paulo: Companhia das Letras, 2008.

HALBWACHS, Maurice. A memória coletiva. São Paulo: Centauro, 2004.

HALLIDAY, Tereza. Discurso organizacional: uma abordagem retórica. In: KUNSCH, Margarida M Krohling (Org.). Comunicação organizacional. Vol 2. Linguagem, gestão e perspectivas. São Paulo: Saraiva, 2009. p. 31-52.

HOBSBAWN, Eric. Sobre história. São Paulo: Companhia das Letras, 1998.

KORNBERGER, Martin; CLEGG, Stewart; CARTER, Chris. Rethinking the polyphonic as discursive practice. Scandinavian Journal of Management, n. 22, p. 3-30, 2006.

MAFFESOLI, Michel. A comunicação sem fim: teoria pós-moderna da comunicação. Famecos - Mídia, Cultura e Tecnologia. Porto Alegre: Faculdade dos Meios de Comunicação Social da PUC-RS, n. 20, abr. 2003.

MATOS, Olgária. Vestígios: escritos de filosofia e crítica social. São Paulo: Palas Athena, 1998.

McLUHAN, Marshall. Os meios de comunicação como extensões do homem (understanding media). São Paulo: Cultrix, 2006.

MEIHY, José Carlos Sebe Bom. Memória, história oral e história. Oralidades - Revista do Núcleo de Estudos em História Oral da USP, n. 8, p. 179-191, jul./dez. 2010.

NASSAR, Paulo. Relações públicas: a construção da responsabilidade histórica e o resgate da memória institucional das organizações. 3. ed. São Caetano do Sul, SP: Difusão; Rio de Janeiro: Senac Rio, 2012.

. História e memória organizacional como interfaces das relações públicas. In: KUNSCH, Margarida M. Krohling (Org.). Relações públicas: história, teorias e estratégias nas organizações contemporâneas. São Paulo: Saraiva, 2009. p. 291-306.

A mãe de todas as responsabilidades. 17 ago. 2007. Disponível em: <http://terramagazine.terra.com.br/ interna/0,011837029-El6786,00-A+mae+de+todas+as + responsabilidades.html>. Acesso em: 01 dez. 2011.

NORA, Pierre. Entre memória e história: a problemática dos lugares. Trad. de Yara Khoury. Projeto História - Revista do Programa de Estudos Pós-Graduados em História, do Departamento de História da PUC-SP, n. 10, p.7-28, dez. 1993.

OLIVEIRA, Ivone de Lourdes. O que é comunicação estratégica nas organizações? São Paulo: Paulus, 2007. 
RIBEIRO, Ana Paula Goulart; BARBOSA, Marialva. Memória, relatos autobiográficos e identidade institucional. Comunicação \& Sociedade, n. 47, p. 99-114, 2007.

SEIXAS, Jacy Alves de. Percursos de memórias em terra de história: problemáticas atuais. In: BRESCIANI, S.; NAXARA, M. (Org.). Memória e (res)sentimento. Campinas: Unicamp, 2001.

TERRA, José Cláudio. Storytelling como ferramenta de gestão. In: Biblioteca Terra Fórum Consultores. São Paulo: [s.d.]. Disponível em: <http://www.terraforum.com.br/biblioteca/ Documents/Storytelling\%20como\%20ferramenta\%20de\%20 gest\%C3\%A3o.pdf>. Acesso em: 21 maio 2010.

THOMPSON, Paul. A voz do passado: história oral. 3. ed. Trad. De Lólio Lorenço de Oliveira. Rio de Janeiro: Paz e Terra, 1992.

VELHO, Gilberto. Memória, cultura e sociedade. In: LEIBING, Annette; BENNINGHOFF-LUHL, Sibylle (Org.). Devorando o tempo:Brasil, o país sem memória. São Paulo: Mandarim, 2001. p. 11ss.

WOOD JR, Thomaz. Uma nau sem rumo. Carta Capital, Confiança, a. 2, p. 20-25, 26 jun.1996.

Artigo recebido em 25.02.2014 e aprovado em 27.03.2014. 